\title{
Period from Loss of the Ability to Access Toilets Independently to Death in End-Stage Cancer Patients
}

\author{
Ryoichi Ichihashi, MD, ${ }^{1,2}$ Kouichi Tanabe, Ph, PhD, ${ }^{3}$ Kenta Horio, MD, Kunihiro Tsuchiya, MD, ${ }^{1}$ \\ Setsuko Hirata, MA, Kaori Gassho, DH, MS, Kazuyo Yasuda, RD, AS, Akina Ishikawa, ST, RD, BS, \\ Kazuki Sato, RN, PHN, PhD, Tatsuya Morita, MD, and Takuya Saiki, MD, MHPE, PhD ${ }^{1,6}$
}

\begin{abstract}
Background: Toileting independence is considered to be important factors for achieving a "good death" for terminally ill patients.

Aim: To clarify the period from loss of the ability to access toilets independently to death in end-stage cancer patients. Design: Observational study.

Setting/Participants: The medical records of all end-stage cancer patients who had died while using home care services provided by Medical Corporation Kagayaki General Home Care Clinic between September 2011 and August 2017, were retrospectively reviewed.

Results: A total of 220 patients were included. The median time from total dependence in toileting to death was 6.0 (95\% confidence interval: 5.0-7.0) days. When the duration was 7 days or shorter and 21 days or shorter, the cumulative death rate was $55.9 \%$ and $86.4 \%$ respectively.

Conclusion: A large percentage of terminally ill cancer patients maintained the ability to access toilets independently until very close to the end of their lives, so the duration of total assistance needed was shorter. These findings may be useful to make a care plan to support achieving "good death" for patients.
\end{abstract}

Keywords: activities of daily living; advanced care planning; cancer; end-of-life care; euthanasia; physicianassisted suicide

\section{Introduction}

T OILETING INDEPENDENCE is a fundamental activity of daily living (ADL), which maintains patients' dignity. ${ }^{1,2}$ In fact, loss of abilities necessary for personal hygiene, walking, and transfer as basic ADL decrease the quality of life, ${ }^{2,3}$ and require advanced caregiving skills. ${ }^{4}$ Families' insufficient caregiving skills may lead to the necessity of hospitalization. ${ }^{5,6}$

Preventing/reducing care dependency, loss of dignity, and heavy caregiving burdens are other important factors, which increase families' and patients' mental distress, and make achieving a good death difficult. Steinhauser, et al. elucidated the concept of a good death", which includes "Affirmation of the Whole Person" as a subconcept. ${ }^{7}$ In the fundamental care, it is emerged that failure to meet the toileting needs affected patients' dignity the most. ${ }^{8}$ For Japanese people, the concept of "Not being a burden to others" contributed to a good death. ${ }^{9}$ If any of the factors that contribute to a good death are missing, a good death may be difficult to achieve, and this could in turn lead patients to consider euthanasia or physician-assisted suicide (PAS) ${ }^{10}$ In these respects, the prediction of survival after declines in ADL, loss of toileting independence, and the provision of related information may contribute to the maintenance of patients' dignity, reduction of caregiving burdens, and decision making regarding the continuation of home care.

\footnotetext{
${ }^{1}$ General Home Care Clinic, Medical Corporation Kagayaki, Gifu, Japan.

${ }^{2}$ Research Institute for Community Health (RICH), Gifu, Japan.

${ }^{3}$ Drug Informatics, Faculty of Pharmacy, Meijo University, Nagoya, Japan.

${ }^{4}$ Department of Nursing, School of Health Sciences, Nagoya University Graduate School of Medicine, Nagoya, Japan.

${ }^{5}$ Department of Palliative and Supportive Care, Seirei Mikatahara Hospital, Hamamatsu, Japan.

${ }^{6}$ Medical Education Development Center, Gifu University, Gifu, Japan.

Accepted June 13, 2018.
}

(C) Ryoichi Ichihashi et al., 2018; Published by Mary Ann Liebert, Inc. This Open Access article is distributed under the terms of the Creative Commons Attribution Noncommercial License (http://creativecommons.org/licenses/by-nc/4.0/) which permits any noncommercial use, distribution, and reproduction in any medium, provided the original author(s) and the source are credited. 
Therefore, this study examined the period from loss of the ability to access toilets independently to death in end-stage cancer patients receiving home care, and additional aim was to explore predictors of death within a short period (1 week).

\section{Methods}

\section{Subjects}

The prospectively collected medical records of all cancer patients who had died using home care services provided by Medical Corporation Kagayaki General Home Care Clinic, primary care clinic with providing specialized palliative care in the community, between September 2011 and August 2017, were retrospectively reviewed. Among these, we included the patients who could access toilets independently on the initial referral and who continued to receive home care without being hospitalized until their death. On the other hand, we excluded those who were unable to excrete independently at the time of the initial home visit, who became bedridden at an unspecified time, and who died suddenly. We defined "Ability to toilet independently" as a sequence of actions: getting out of bed; moving to toilet; excreting; getting back to bed, independently without any support. Therefore, "loss of ability to toilet" implies that there was a problem in the sequence of actions.

\section{$A D L$ and survival calculation}

The duration of total assistance, which was defined as the period from loss of the ability to access toilets independently until death, was individually investigated.

\section{Study items}

The study items were as follows: the age and gender; scores from the Eastern Cooperative Oncology Group (ECOG) Performance Status (PS), Palliative Prognostic Index (PPI), ${ }^{11}$ and Prognosis in Palliative Care Study Predictor Models-A (PiPsA) ${ }^{12}$; the history of cerebrovascular/neurological disorder or spinal disease; the presence/absence of dyspnea, lower limb paralysis, delirium, loss of appetite, a $5 \%$ or more marked decrease in the body weight within one month, dysphagia, lower limb edema, pressure ulcers, and an established diagnosis of dementia; vital signs (systolic blood pressure, heart rate, respiratory rate, oxygen saturation level, and body temperature) on the day when it became difficult to access toilets independently; the necessity of oxygen inhalation, fluid therapy, urinary catheterization, and fecal disimpaction; presence/ absence of hepatic, bone, or distant metastasis (excluding those to the liver/bone); duration of disease; opioid use; family structure (solitary/nonsolitary); and primary lesion.

\section{Statistical analysis}

A Kaplan-Meier curve was created based on the duration of total assistance and survival rates. In addition, the patients were divided into three groups based on their durations of total assistance: 7 days or shorter, 14 days or shorter, and 21 days or shorter, to calculate the proportion of each group.

Patients who died within one week and those who survived longer were divided into shorter and longer survival groups, respectively, to perform univariate analysis. Multiple logistic regression analysis was also performed using dyspnea,

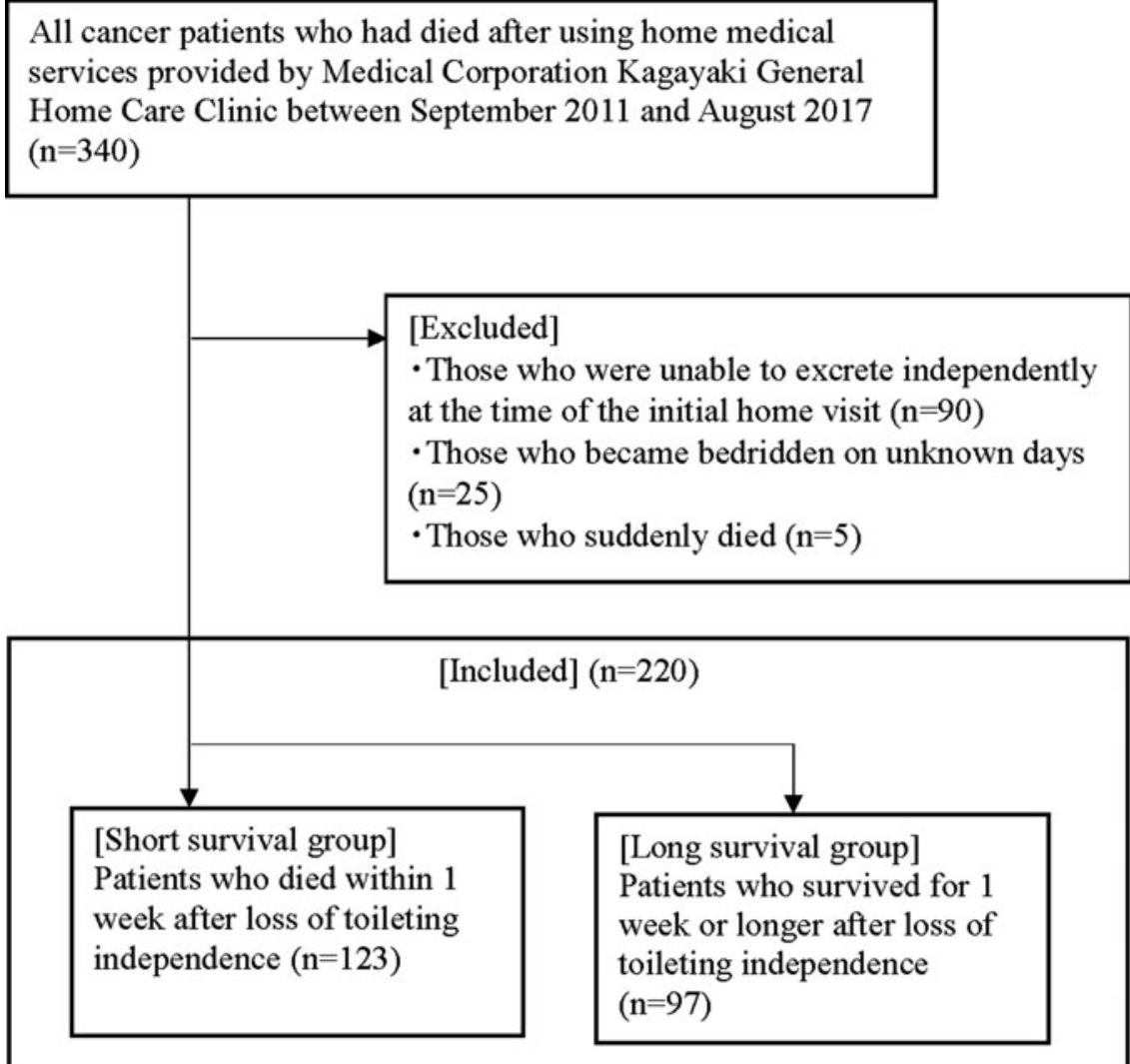

FIG. 1. Subject inclusion flowchart. 
delirium, loss of appetite, and PS scores, which are considered as prognostic predictors for the PPI, ${ }^{11}$ in addition to factors showing $p<0.2$ in univariate analysis.

Data collected through the medical record review were descriptively and statistically summarized and quantified as mean \pm standard deviations or medians and ranges (minimummaximum values). For comparison among the groups, the $t$ test, Mann-Whitney $U$ test, chi-square test, or Fisher's exact test were used, according to the type of data. Multiple logistic regression analysis was based on the stepwise method for variable selection. The significance level was set at 0.05 in all cases. All these statistical procedures were performed using SPSS version 22 (IBM Japan Ltd., Tokyo).

\section{Ethical considerations}

The study was conducted with the approval of the Ethics Committee of General Home Care Clinic (approval number: 2017-01).

\section{Results}

\section{Patients' backgrounds}

Excluding those who were unable to excrete independently at the time of the initial home visit (90), those who became bedridden at an unspecified time (25), and those who suddenly died (5: bleeding from the tumor: 1, ruptured esophageal varix:

Table 1. Patients' Backgrounds When Included (When It Became Difficult TO ACCESS TOILETS INDEPENDENTLY)

\begin{tabular}{|c|c|c|c|}
\hline Items & $\begin{array}{l}\text { Shorter survival } \\
\text { group }(\mathrm{n}=123)\end{array}$ & $\begin{array}{l}\text { Longer survival } \\
\text { group }(\mathrm{n}=97)\end{array}$ & $\mathrm{p}$ \\
\hline Age (years, mean $\pm S D$ ) & $73.2 \pm 11.8$ & $73.9 \pm 11.9$ & 0.68 \\
\hline Sex ( $n$, male/female) & $78 / 45$ & $49 / 48$ & 0.054 \\
\hline ECOG Performance Status $(n, 0 / 1 / 2 / 3 / 4)$ & $0 / 9 / 32 / 58 / 24$ & $2 / 3 / 20 / 46 / 26$ & 0.51 \\
\hline Palliative Prognostic Index (mean \pm SD) & $5.1 \pm 3.0$ & $5.1 \pm 2.7$ & 0.86 \\
\hline PiPs-A ( $n$, days/weeks/months) & $29 / 59 / 35$ & $21 / 49 / 27$ & 0.95 \\
\hline $\begin{array}{l}\text { History of cerebrovascular/neurological disorder or spinal disease } \\
\quad(n, \text { yes/no) }\end{array}$ & $3 / 120$ & $8 / 89$ & 0.050 \\
\hline Dyspnea ( $n$, yes/no) & $41 / 82$ & $25 / 72$ & 0.22 \\
\hline Lower limb paralysis ( $n$, yes/no) & $3 / 120$ & $11 / 86$ & 0.007 \\
\hline Delirium $(n$, yes/no $)$ & $17 / 106$ & $15 / 82$ & 0.73 \\
\hline Loss of appetite ( $n$, yes/no) & $119 / 4$ & $86 / 11$ & 0.018 \\
\hline $\begin{array}{l}\text { A } 5 \% \text { or more marked decrease in the body weight within one month } \\
(n, y e s / n o)\end{array}$ & $109 / 14$ & $78 / 19$ & 0.091 \\
\hline Dysphagia ( $n$, yes/no) & $19 / 104$ & $10 / 87$ & 0.26 \\
\hline Lower limb edema ( $n$, yes/no) & $29 / 94$ & $20 / 77$ & 0.60 \\
\hline Pressure ulcers ( $n$, yes/no) & $5 / 118$ & $13 / 84$ & 0.012 \\
\hline Dementia (n, yes/no) & $4 / 119$ & $14 / 83$ & 0.003 \\
\hline Systolic blood pressure $(\mathrm{mmHg}$, mean $\pm \mathrm{SD})$ & $104 \pm 20$ & $112 \pm 18$ & 0.004 \\
\hline Heart rate (times/minutes, mean $\pm \mathrm{SD}$ ) & $92.3 \pm 18.7$ & $88.4 \pm 17.5$ & 0.12 \\
\hline Respiratory rate (times/minutes, mean $\pm \mathrm{SD}$ ) & $19.9 \pm 7.4$ & $19.6 \pm 6.6$ & 0.86 \\
\hline Oxygen saturation level $(\%$, mean $\pm \mathrm{SD})$ & $92.9 \pm 10.3$ & $93.9 \pm 9.8$ & 0.44 \\
\hline Oxygen inhalation (L/minutes, mean $\pm \mathrm{SD})$ & $1.6 \pm 8.6$ & $0.6 \pm 1.1$ & 0.26 \\
\hline Body temperature $\left({ }^{\circ} \mathrm{C}\right.$, mean $\left.\pm \mathrm{SD}\right)$ & $36.6 \pm 0.8$ & $36.6 \pm 0.6$ & 0.58 \\
\hline Fluid therapy ( $n$, yes/no) & $19 / 104$ & $13 / 84$ & 0.67 \\
\hline Urinary catheterization $(n$, yes/no) & $32 / 91$ & $43 / 54$ & 0.004 \\
\hline Fecal disimpaction ( $n$, yes/no) & $23 / 100$ & $40 / 57$ & $<0.001$ \\
\hline Hepatic metastasis ( $n$, yes/no) & $34 / 89$ & $19 / 78$ & 0.17 \\
\hline Bone metastasis $(n$, yes/no) & $15 / 108$ & $20 / 77$ & 0.090 \\
\hline Distant metastasis (excluding those to the liver/bone) ( $n$, yes/no) & $75 / 48$ & $71 / 26$ & 0.057 \\
\hline Duration of disease (months, mean $\pm \mathrm{SD}$ ) & $24.0 \pm 32.3$ & $30.9 \pm 52.5$ & 0.23 \\
\hline Opioid use $(n$, yes/no) & $78 / 45$ & $53 / 44$ & 0.19 \\
\hline Solitary ( $n$, yes/no) & $4 / 119$ & $9 / 88$ & 0.060 \\
\hline Primary lesion $(n)$ & & & 0.61 \\
\hline Lung & 20 & 23 & \\
\hline Stomach/esophagus & 15 & 18 & \\
\hline Liver/gallbladder/pancreas & 16 & 36 & \\
\hline Large intestine & 14 & 12 & \\
\hline Hematopoietic organs & 5 & 10 & \\
\hline Urinary organs & 9 & 6 & \\
\hline Prostate & 5 & 6 & \\
\hline Breast & 4 & 4 & \\
\hline Uterus/ovary & 4 & 5 & \\
\hline Others & 5 & 3 & \\
\hline
\end{tabular}

ECOG; PiPs-A: Prognosis in Palliative care Study predictor models-A; SD, standard deviation. 


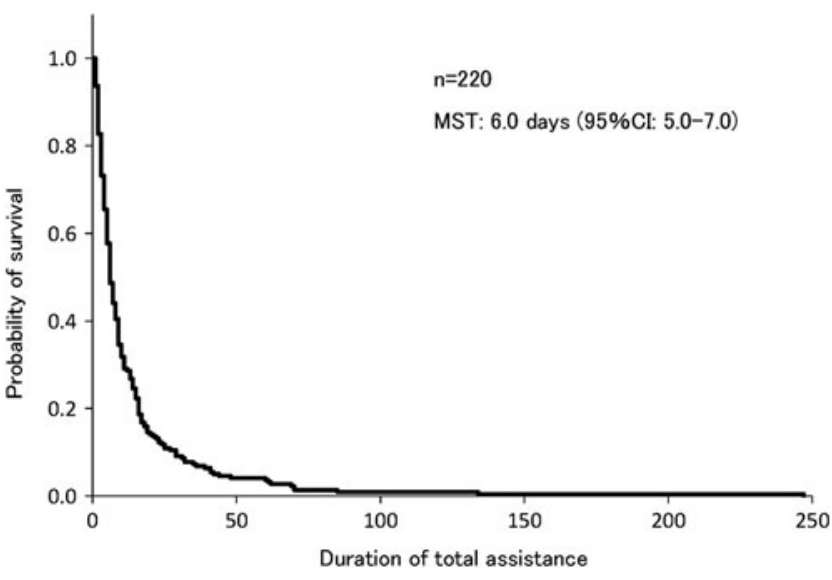

FIG. 2. Expected survival times. The duration of total assistance was defined as a period from loss of toileting independence to death. CI, confidence interval; MST, median survival time.

1, cardiac infarction: 1 , cerebral hemorrhage: 1 , and unknown cause: 1), 220 patients were included (Fig. 1). All patients used home care services. Table 1 outlines the patients' backgrounds when included.

\section{Primary endpoint: $A D L$ and expected survival times}

The median duration of total assistance was 6.0 (95\% confidence interval: 5.0-7.0) days (Fig. 2). The cumulative death rate for each duration of total assistance was as follows: 7 days or shorter: $55.9 \%, 14$ days or shorter: $75.5 \%$, and 21 days or shorter: $86.4 \%$ (Fig. 3 ).

\section{Predictors of death within one week}

In these cases, hepatic metastasis and loss of appetite increased the probability of death within one week. Positive factors for a one-week or longer survival were lower limb

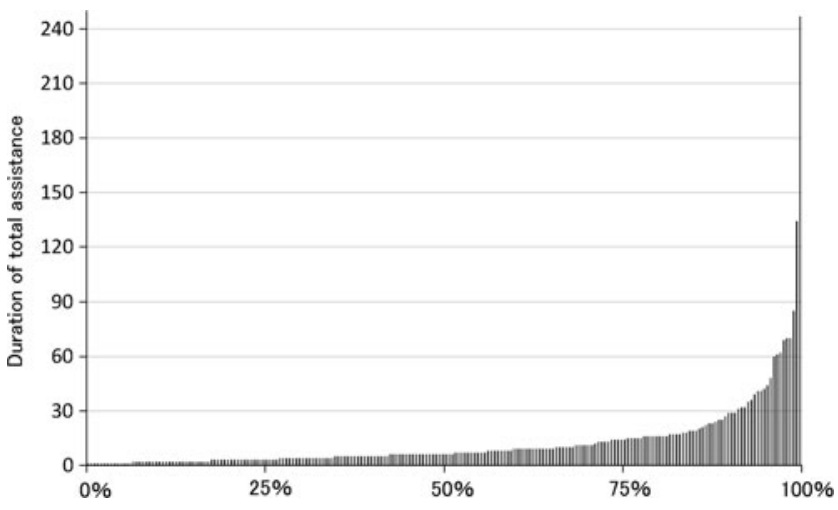

FIG. 3. Duration of total assistance and its distribution. The longitudinal axis indicates the period from the initiation of total assistance (loss of toileting independence) to death (duration of total assistance). Each bar represents the duration of total assistance required for each patient. From the left to right, the length of the bar or the duration increases $(n=220)$. During the period of total assistance, $50 \%, 75 \%$, and $90 \%$ of patients died within 6, 14, and 27 days, respectively.
Table 2. Predictors of Death within One Week

\begin{tabular}{lccc}
\hline $\begin{array}{l}\text { Explanatory } \\
\text { variable (factor) }\end{array}$ & $\mathrm{p}$ & $\begin{array}{c}\text { Odds } \\
\text { ratio }\end{array}$ & $\begin{array}{c}95 \% \text { confidence } \\
\text { interval }\end{array}$ \\
\hline Loss of appetite & 0.049 & 5.14 & $1.01-26.27$ \\
Hepatic metastasis & 0.006 & 3.08 & $1.39-6.84$ \\
Distant metastasis & 0.009 & 0.36 & $0.17-0.78$ \\
Pressure ulcers & 0.049 & 0.31 & $0.09-0.99$ \\
Lower limb paralysis & 0.026 & 0.20 & $0.05-0.83$ \\
Dementia & 0.001 & 0.14 & $0.04-0.47$ \\
\hline
\end{tabular}

paralysis due to metastatic cancer, pressure ulcers, dementia, and distant metastasis, excluding those to the liver. Related significant differences, among dyspnea, an abnormal heart rate, and leukemia were not observed (Table 2).

\section{Discussion}

The results clarified the survival distribution of patients requiring total assistance. Notably, the present study demonstrated that the walking ability of cancer patients receiving home care is maintained to some extent until their last days, and the median period from loss of mobility until death is as short as six days. It is known that various vital reactions occur at the end of life, following a rapid loss of mobility due to declines in ADL. ${ }^{13,14}$ It is inevitable that the ability to access toilets independently gradually decreases. A prolonged period of the loss of mobility to access toilets independently could in turn lead to a loss of patients dignity and thus potentially increase the risk of euthanasia/PAS. ${ }^{15}$ Additionally, when supporting home care users, excretion management is a common challenge, occasionally leading to the necessity of hospital admission in Japan. ${ }^{6}$ However, the present study indicated that the duration of total assistance is actually short, and patients' and their families' care-related burdens may not be as heavy as previously considered. For the aforementioned reasons, loss of dignity, and the risk of euthanasia/PAS might be limited at least in cancer patients.

Another interesting finding was that hepatic metastasis and appetite loss increase the probability of death within one week. To date, prognostic predictors of death within a short period ( 1 week) have been examined only using biomarkers, ${ }^{16}$ and the majority of such tools are designed to predict survival times longer than three weeks. ${ }^{17}$ Our results suggested marked influences of metastasis to major organs and loss of the ability to orally ingest nutrients on the prognosis. ${ }^{18,19}$ As tools to predict the one-week prognosis based on specific clinical symptoms are unavailable at present, the factors shown to be associated with death within one week in the present study may prove important for patients' and families' decisions on continuing home care.

The study has some limitations: First, as this is a retrospective single-center study, the generalization of the results should be considered in future studies. However, the similarity between the curve of survival shown in Figure 1 and that representing the rate of losing mobility immediately before death ${ }^{13}$ may support the conclusions. Second, it was difficult to clarify the exact moment when the patients' mobility was lost, and it only covered the patients who died. These may have led to the estimation of their survival times at slightly lower than actual values. Third, 
there may have been unmeasured, unknown confounders. Finally, the backgrounds of patients admitted to hospitals remained unclear, and hospitalization itself may have resulted in a selection bias.

Despite these limitations, this study may be useful to reduce patients' and their families' psychological burden regarding excretion care. The provision of these findings to patients and families may also prevent undesired, unplanned hospital admission and euthanasia/PAS, consequently allowing patients to die naturally in their homes, with their dignity maintained.

\section{Conclusion}

Nearly half of the home care cancer patients were able to access toilets and excrete independently until one week before death, revealing that the period from loss of such an ability until death is short. As these findings may support patients' and families' decision making, they should be reexamined in prospective studies and shared among healthcare professionals in end-of-life care.

\section{Author Disclosure Statement}

The authors declared no potential conflicts of interest with respect to the research, authorship, and/or publication of this article.

\section{References}

1. Matsushima E, Noguchi W: Dignity of cancer patients. Jpn J Psychiat Neurol 2009;111:73-77.

2. Neo J, Fettes L, Gao W, et al.: Disability in activities of daily living among adults with cancer: A systematic review and meta-analysis. Cancer Treat Rev 2017;61:94-106.

3. Maeda A, Hata Y, Mihara N, et al.: Excretion environment adjustment for a terminal cancer patient: Excretion care given by a team. Palliat Car Res 2014;9:920-923.

4. Matsunobu R, Kawa F, Saeki N, et al.: The case of hospital death who was not able to continue home care. Jpn J Home Care Nurs 2009;14:154-157.

5. Gomes B, Higginson IJ: Factors influencing death at home in terminally ill patients with cancer: Systematic review. BMJ 2006;332:515-521.

6. Tanabe K, Sawada K, Shimada M, et al.: Evaluation of a novel information-sharing instrument for home-based palliative care: A feasibility study. Am J Hosp Palliat Care 2015;32:611-619.

7. Steinhauser KE, Clipp EC, McNeilly M, et al.: In search of a good death: Observations of patients, families, and providers. Ann Intern Med 2000;132:825-832.
8. Dean E: Dignity in toileting. Nurs Stand 2012;26:18-20.

9. Akechi T, Miyashita M, Morita T, et al.: Good death in elderly adults with cancer in Japan based on perspectives of the general population. J Am Geriatr Soc 2012;60:271-276.

10. Kouwenhoven PS, van Thiel GJ, Raijmakers NJ, et al.: Euthanasia or physician-assisted suicide? A survey from the Netherlands. Eur J Gen Pract 2014;20:25-31.

11. Morita T, Tsunoda J, Inoue S, et al.: The Palliative Prognostic Index: A scoring system for survival prediction of terminally ill cancer patients. Support Care Cancer 1999;7: 128-133.

12. Gwilliam B, Keeley V, Todd C, et al.: Development of Prognosis in Palliative care Study (PiPS) predictor models to improve prognostication in advanced cancer: Prospective cohort study. BMJ Support Palliat Care 2015;5:390-398.

13. Tsuneto $S$ : The chapter 1: Introduction. In: Tsuneto $S$ (ed): The Latest Palliative Medicine, 1st ed. Osaka, Japan: Saishin Igaku Co. Ltd., 1999, pp. 1-46.

14. Sands MB, Piza M, Ingham JM: The epidemiology of the end-of-life experience. In Hanks G, Cherney N, Christakis NA, Fallon M, Kaasa S, Portenoy RK (eds): Oxford Textbook of Palliative Medicine, 4th ed. Oxford, United Kingdom: Oxford University Press, 2009, pp. 58-80.

15. Lachenmeier F, Kaplan KJ, Caragacianu D: Doctor assisted suicide: An analysis of public opinion of Michigan adults. Omega (Westport) 1999-2000;40:61-87.

16. Okugawa Y, Shirai Y, Nodono H, et al.: Objective predictive score as a feasible biomarker for short-term survival in terminally ill patients with cancer. Anticancer Res 2017; 37:267-275.

17. Simmons CPL, McMillan DC, McWilliams K, et al.: Prognostic tools in patients with advanced cancer: A systematic review. J Pain Symptom Manage 2017;53:962-970.e10.

18. Valderrama-Treviño AI, Barrera-Mera B, Ceballos-Villalva JC, et al.: Hepatic metastasis from colorectal cancer. Euroasian J Hepatogastroenterol 2017;7:166-175.

19. Matsunuma R, Tanbo Y, Asai N, et al.: Prognostic factors in patients with terminal stage lung cancer. J Palliat Med 2014;17:189-194.

Address correspondence to: Ryoichi Ichihashi, MD

Research Institute for Community Health (RICH) 4-12 Yakushiji Ginan-cho Hashima-gun Gifu Prefecture 501-6014 Japan

E-mail: richihashi@sogo-zaitaku.jp 